\title{
IMPLEMENTASI DANA KARTU JAKARTA PINTAR (KJP) (Sebuah Analisis Kebijakan Pendidikan)
}

\author{
Ali Nurdin \\ UIN Syarif Hidayatullah Jakarta \\ ali010655@yahoo.com
}

\begin{abstract}
Education is one of the determinants of the nation's progress in the future. To create education that can support its progress, all components of the nation must be integrated and support educational programs and policies. Jakarta Smart Card as a new breakthrough in the world of education in DKI Jakarta Province, comes as a support for investing in education. The purpose of writing this journal is to analyze the policies of the DKI Jakarta Provincial Government in the form of providing education funding through Smart Jakarta Cards, both in terms of the amount of fees obtained and other benefits that can be enjoyed by recipients of these funds. This research is descriptive qualitative research in the form of literature studies where the data collected will be analyzed supported by comprehensive observations on the existence of KJP, its essence and substance in improving the quality of education in DKI Jakarta to date. This study concludes that government involvement in education funding is the right step in an investment towards a developed nation, with a record of being managed well and on target.
\end{abstract}

Keywords: KJP, amount of costs, benefits of KJP

\begin{abstract}
ABSTRAK
Pendidikan adalah salah satu faktor penentu kemajuan bangsa pada masa depan. Untuk menciptakan pendidikan yang dapat menunjang kemajuannya, seluruh komponen bangsa tersebut harus terintegrasi dan mendukung program dan kebijakan pendidikan. Kartu Jakarta Pintar sebagai sebuah terobosan baru dalam dunia pendidikan di Provinsi DKI Jakarta, hadir sebagai suatu dukungan guna berinvestasi dalam pendidikan. Tujuan penulisan jurnal ini adalah untuk menganalisa kebijakan Pemerintah Provinsi DKI Jakarta berupa pemberian bantuan dana Pendidikan melalui Kartu Jakarta Pintar, baik itu pengertian, besaran biaya yang didapatkan dan manfaat lain yang bisa dinikmati penerima dana tersebut. Penelitian ini adalah penelitian kualitatif deskriptif dalam bentuk studi pustaka; data yang dikumpulkan akan dianalisis yang didukung oleh hasil pengamatan komprehensif mengenai eksistensi KJP, esensi dan substansinya dalam peningkatan mutu pendidikan di DKI Jakarta hingga saat ini. Penelitian ini menyimpulkan bahwa keterlibatan pemerintah dalam pembiayaan pendidikan merupakan langkah tepat dalam sebuah investasi menuju bangsa maju, dengan catatan dikelola dengan baik dan sesuai sasaran.
\end{abstract}




\section{A. PENDAhuluan}

Mendidik manusia merupakan sebuah investasi bagi kemajuan bangsa di masa yang akan datang. Dengan kata lain, sebuah bangsa dikatakan maju manakala Sumber Daya Manusia (SDM) yang ada pada bangsa itu mendapatkan pendidikan.

Di antara sekian banyak agenda pembangunan bangsa, pendidikan merupakan salah satu agenda penting dan strategis yang menuntut perhatian sungguh-sungguh dari semua pihak. Hal itu disebabkan karena pendidikan adalah faktor penentu kemajuan bangsa pada masa depan. Mulyono menyatakan bahwa Pendidikan merupakan salah satu bentuk investasi modal manusia (human investment) yang akan menentukan kualitas Sumber Daya Manusia (SDM) suatu bangsa. ${ }^{1}$

Saat memasuki dekade 1980-an, sebagian besar masyakat Indonesia tidak sampai tamat pendidikan dasar yang dahulu di masa Belanda sampai di tahun 1950-1960-an lebih di kenal dengan nama Sekolah Rakyat (SR), dengan masa belajar selama 6 tahun. Setelah satu dasawarsa pencanangan program Wajib Belajar Pendidikan Dasar enam tahun sejak tahun 1984, pada tahun 1994 melalui Inpres Nomor 1 Tahun 1994 ditingkatkan menjadi Program Wajib Belajar Pendidikan Dasar 9 Tahun. Hal ini berarti bahwa setiap anak Indonesia yang berumur 7-15 tahun diwajibkan untuk mengikuti Pendidikan Dasar 9 tahun sampai tamat Sekolah Menengah Pertama (SMP). Namun, masih cukup banyak masyarakat Indonesia yang belum tamat setingkat pendidikan dasar. Permasalahan-permasalahan tersebut bukan semakin memudar, justru semakin mengkristal dan melahirkan masalah-masalah baru. Program-program baru pun muncul sebagai penunjang Wajardikdas 9 Tahun ini seperti: SMP Terbuka, SD-SMP Satu Atap, USB, dll. ${ }^{2}$

Dalam beberapa dekade, alokasi anggaran pendidikan masih di bawah $10 \%$ dari APBN dan lebih rendah dibandingkan dengan sektor yang berorientasi investasi fisik seperti pekerjaan umum. Maka mulai tahun 2009, anggaran pendidikan dinaikkan relatif tinggi mencapai $20 \%$ dari APBN sehingga menempati urutan pertama di antara lima sektor yang memperoleh anggaran pembangunan paling besar yakni Pendidikan, Pekerjaan Umum, Kesehatan, Pertanian dan Hankam.

Peningkatan alokasi anggaran ini terutama dimaksudkan untuk mencapai dua sasaran utama, yakni peningkatan mutu dan pemerataan pendidikan. Peningkatan mutu pendidikan berkaitan dengan ketersediaan sarana yang baik, fasilitas laboratorium, peralatan, perpustakaan serta buku yang memadai, dan yang amat vital adalah ketersediaan tenaga pengajar (guru) yang berkualitas. Sementara pemerataan pendidikan bertujuan untuk memperluas akses agar seluruh masyarakat dapat memperoleh kesempatan pendidikan. ${ }^{3}$

Provinsi DKI Jakarta adalah daerah khusus yang berfungsi sebagai Ibukota Negara Kesatuan Republik Indonesia dan sekaligus sebagai daerah otonom pada tingkat provinsi. Otonomi Provinsi DKI Jakarta diletakkan pada tingkat provinsi. Penyelenggaraan Pemerintahan Provinsi DKI Jakarta dilaksanakan menurut asas otonomi, asas dekonsentrasi, asas tugas pembantuan, dan kekhususan sebagai Ibukota Negara Kesatuan Republik Indonesia. ${ }^{4}$

\footnotetext{
${ }^{1}$ Mulyono, Konsep Pembiayaan Pendidikan. 65.

2 Daroesman, Pembiayaan Pendidikan di Indonesia: Sebuah Studi tentang Sumber dan Penggunaan Pembiayaan Pendidikan. 3-7.

${ }^{3}$ Mulyono, Konsep Pembiayaan Pendidikan. 71-73.

4 "https://id.wikipedia.org." 
Karena pentingnya pendidikan sebagai hak tiap warga negara Indonesia, Pemerintah provinsi DKI Jakarta, mengucurkan dana APBD-nya untuk meluncurkan Program Kartu Jakarta Pintar (KJP) dalam pendanaan pendidikan sebagai upaya peningkatan mutu anak didik yang bersekolah di Jakarta, terhitung sejak 1 Desember 2012. Program KJP ini diperuntukkan bagi siswa miskin, yaitu peserta didik pada jenjang satuan pendidikan Sekolah Dasar sampai dengan Sekolah Menengah yang secara personal dinyatakan tidak mampu baik secara materi maupun penghasilan orang tuanya yang tidak memadai untuk memenuhi kebutuhan dasar pendidikan.

Badan Pusat Statistik (BPS) mencatat persentase penduduk miskin di DKI Jakarta pada bulan September 2017 mencapai 3,78 persen yang berarti mencakup sejumlah 393,13 ribu orang. Dibandingkan dengan Maret 2017 (3,77\% atau 389,69 ribu orang), persentase penduduk miskin meningkat 0,01 poin atau meningkat sebesar 3,44 ribu orang. Sedangkan dibandingkan dengan September 2016 (3,75\% atau 385,84 ribu orang), persentase penduduk miskin meningkat 0,03 poin atau meningkat sebesar 7,29 ribu orang. 5

\section{B. METODE PENELITIAN}

Tulisan ini membahas tentang Implementasi Dana KJP. Metode yang digunakan dalam penulisan jurnal ini adalah analisis deskriptif deduktif induktif melalui studi literatur, dengan mencari teori yang relevan. Data yang dikumpulkan akan dianalisis komprehensif terkait eksistensi KJP, esensi dan substansinya dalam peningkatan mutu pendidikan di DKI Jakarta hingga saat ini.

Literatur utama atau primer yang dikaji dalam penelitian ini adalah berbagai artikel tentang Kartu Jakarta Pintar (KJP), jurnal, dan berita yang membahas KJP. Metode pengumpulan data yang digunakan adalah metode dokumentasi, yaitu data tentang variabel yang berupa buku, jurnal, laman, dan lain sebagainya.

\section{TEMUAN DAN PEMBAHASAN}

\section{Gambaran Umum Kartu Jakarta Pintar (KJP)}

\section{a. Pengertian Kartu Jakarta Pintar (KJP)}

Kartu Jakarta Pintar mulai dipopulerkan oleh mantan Gubernur DKI Joko Widodo sebagai program strategis untuk memberikan akses bagi warga DKI Jakarta dari kalangan masyarakat tidak mampu untuk mengenyam pendidikan minimal sampai dengan tamat SMA/SMK dengan dibiayai penuh dari dana APBD Provinsi DKI Jakarta. ${ }^{6}$

Adapun untuk tahun 2018 setelah DKI Jakarta dipimpin oleh Anies Rasyid Baswedan dan Sandiaga Uno, program KJP disempurnakan menjadi KJP Plus sebagai perwujudan salah satu janji kampanye mereka saat bersaing dalam Pilkada tahun lalu. KJP Pus dimaksud untuk merevisi dan memperluas manfaat Kartu Jakarta Pintar dalam bentuk Kartu Jakarta Pintar Plus untuk semua anak usia sekolah (6-21 tahun). Juga dapat digunakan untuk Kelompok Belajar Paket A, B dan C, pendidikan Madrasah, Pondok Pesantren dan kursus keterampilan serta dilengkapi dengan bantuan tunai untuk keluarga tidak mampu. $^{7}$

\footnotetext{
5 "Badan Pusat Statistik Provinsi DKI Jakarta, Statistik Kesejahteraan Rakyat Provinsi DKI Jakarta 2017."

6 T.t.

${ }^{7}$ Peb 2017.
}

Al Amin:Jurnal Kajian Ilmu dan Budaya Islam, Volume 2, No 1, 2019|51 
Selain KJP, Pemprov DKI Jakarta juga menyiapkan dana bantuan pendidikan lanjutan yang berupa Kartu Jakarta Mahasiswa Unggul (KJMU) dengan syarat telah menerima dana KJP di jenjang pendidikan sebelumnya. Adapun untuk tahun 2018, siswa kelas XII diberikan dana program bridging (persiapan seleksi masuk Perguruan Tinggi) sebesar Rp. 500.000,- yang dapat dialokasikan untuk biaya les, beli buku atau beli formulir.

Regulasi-regulasi yang terkait dengan kebijakan Kartu Jakarta Pintar antara lain: 1). Peraturan Gubernur KJP Plus No. 04 Tahun 2018 tentang Bantuan Biaya Personal Pendidikan Bagi Peserta Didik Dari Keluarga Tidak Mampu Melalui Kartu Jakarta Pintar; 2). Peraturan Daerah No. 12 Tahun 2014 tentang Organisasi Perangkat Daerah; 3). Peraturan Gubernur DKI No. 133 Tahun 2014 tentang Pembentukan Organisasi dan Tata Kerja Pusat Perencanaan Dan Pengendalian Pendanaan Pendidikan Personal Dan Operasional; 4). Instruksi KADISDIK Nomor 1 Tahun 2017 tentang Pendataan Calon Penerima Bantuan Personal Pendidikan Bagi Peserta Didik Dari Keluarga Tidak Mampu Melalui Kartu Jakarta Pintar (KJP) Tahap 1 Tahun 2017; 5). ${ }^{8}$ Surat Edaran Nomor SE/3/2017; dan 6). Peraturan Gubernur DKI No. 133 Tahun 2016 tentang Bantuan Biaya Peningkatan Mutu Pendidikan bagi Mahasiswa dari keluarga tidak mampu. ${ }^{9}$

Hal di atas menggambarkan tentang betapa kuat dukungan pemerintah Provinsi DKI Jakarta dan mengharapkan dana KJP yang akan diterima benar-benar tepat sasaran dan tepat guna demi terselenggaranya Wajib Belajar bagi seluruh warga DKI Jakarta. Dengan demikian, pendidikan sebagai investasi masa depan akan terbukti, salah satunya dengan program KJP ini. Warga DKI Jakarta di masa yang akan datang mampu membangun Ibukota menjadi lebih baik dan lebih maju.

\section{b.Sasaran KJP}

Sasaran dari program KJP adalah siswa miskin, yaitu peserta didik pada jenjang satuan pendidikan sekolah dasar sampai dengan menengah yang secara personal dinyatakan tidak mampu baik secara materi maupun penghasilan orang tuanya yang tidak memadai untuk memenuhi kebutuhan dasar pendidikan. Kebutuhan dasar yang dimaksud mencakup: seragam, sepatu, tas sekolah, biaya transportasi, makanan serta biaya ekstrakurikuler.

Siswa miskin yang berhak mendapatkan dana KJP/KJP Plus harus memenuhi syarat-syarat sebagai berikut: 1). Warga DKI Jakarta (Kartu Keluarga atau surat keterangan); 2). Membuat surat pernyataan tidak mampu/miskin yang diketahui orang tua dan Ketua Rukun Tetangga (RT) setempat; 3). Terdaftar dan masih aktif di salah satu satuan pendidikan di Provinsi DKI Jakarta; 4). Diusulkan oleh sekolah yang telah ditandatangani oleh Kepala Sekolah, Kepala Satuan Pelaksana Pendidikan kecamatan setempat yang selanjutnya diajukan ke Suku Dinas/Dinas Pendidikan setempat; dan 5). Menandatangani lembar Fakta Integritas yang telah disediakan.

Untuk mendapatkan KJP/KJP Plus siswa terkait diusulkan satu tahun 2 kali (setiap semester) dari pendataan sekolah, dimana akan dilakukan peninjauan lapangan langsung guna memastikan kelayakan ekonomi siswa tersebut sehingga dana KJP/KJP Plus sesuai dengan ketentuan dan tepat sasaran.

Selain syarat-syarat di atas, ada kriteria yang ikut menentukan kelayakan menerima dana KJP, yaitu: 1). Tidak merokok dan atau mengkonsumsi narkoba; 2). Orang tua tidak memiliki penghasilan yang memadai; 3). Menggunakan angkutan umum; 4). Daya beli

\footnotetext{
8 "Instruksi KADISDIK Nomor 1 Tahun 2017."

9 "Surat Edaran Nomor SE/3/2017."
} 
untuk sepatu dan pakaian seragam sekolah/pribadi rendah; 5). Daya beli untuk buku, tas dan alat tulis rendah; 6). Daya beli untuk konsumsi makan/jajan rendah; 7). Daya pemanfaatan internet rendah; dan 8). Tidak dapat mengikuti kegiatan ekstrakurikuler yang berpotensi mengeluarkan biaya.

Pada kenyataannya, tahun 2018 ini pendataan calon penerima dana KJP benarbenar menjadi tanggung jawab pihak sekolah, dari pemberkasan, pengecekan kesesuaian kriteria, survey langsung ke tempat tinggal siswa yang mengusulkan, hingga monitoring data siswa yang dinyatakan layak menerima dana KJP tersebut.

\section{c. Besaran dan Pencairan Dana KJP}

Dana KJP masuk ke rekening tabungan Monas di Bank DKI milik siswa untuk 1 semester sekaligus. Untuk pengambilan dana dibatasi per 2 minggu sesuai tingkatan masing-masing siswa (setiap tanggal 1 dan 15 setiap bulan). Dana KJP hanya dapat digunakan untuk belanja di toko perlengkapan pendidikan bermesin EDC/ gesek Bank DKI atau jaringan Prima (BCA) dengan menggunakan Kartu ATM KJP. Dana KJP tidak dapat ditarik tunai baik di teller maupun ATM. Dana yang belum digunakan tidak akan hangus dan akan menjadi tabungan siswa. Penggunaan EDC bank selain Bank DKI dikenakan biaya sesuai ketentuan antar bank.

Dari laman resmi KJP, alokasi dana KJP yang direvisi menjadi KJP Plus sesuai dengan jenjang pendidikan diperoleh gambaran sebagai berikut:

\begin{tabular}{|l|l|l|l|}
\hline \multicolumn{1}{|c|}{ Jenjang } & \multicolumn{1}{|c|}{ KJP } & KJP Plus & Selisih \\
\hline SD/MI/SDLB & Rp. 210.000,- & Rp. 250.000,- & Rp. 40.000,- \\
\hline SMP/Mts/SMPLB & Rp. 260.000,- & Rp. 300.000,- & Rp. 40.000,- \\
\hline SMAN/MAN/SMALBN & Rp. 375.000,- & \multirow{2}{*}{ Rp. 420.000,- } & Rp. 45.000,- \\
\cline { 1 - 2 } SMA/MA/SMALB & Rp. 390.000,- & & Rp. 30.000,- \\
\hline SMK/SMKN & Rp. 390.000,- & Rp. 450.000,- & Rp. 60.000,- \\
\hline PKBM & Rp. 210.000,- & Rp. 300.000,- & Rp. 90.000,- \\
\hline
\end{tabular}

Untuk sekolah swasta, terdapat tambahan SPP per-bulannya, yaitu:

\begin{tabular}{|l|l|l|}
\hline \multicolumn{1}{|c|}{ Jenjang } & \multicolumn{1}{c|}{ KJP } & KJP Plus \\
\hline SD/MI/SDLB & Rp. 130.000,- & Rp. 130.000,- \\
\hline SMP/Mts/SMPLB & Rp. 170.000,- & Rp. 170.000,- \\
\hline SMA/MA/SMALB & Rp. 275.000,- & Rp. 290.000,- \\
\hline SMKN & Rp. 240.000,- & Rp. 240.000,- \\
\hline
\end{tabular}

Dari data di atas, terlihat bahwa besaran dana KJP yang direvisi menjadi KJP Plus mengalami peningkatan. Sehingga tidak heran jika APBD DKI Jakarta tahun 2018 untuk KJP Plus bertambah Rp. 560 miliar menjadi 3,9 Triliun, yang juga dialokasikan untuk anak usia sekolah yang putus sekolah dan dana persiapan masuk ke Perguruan Tinggi.

\section{d. Penggunaan Dana KJP}

Dana KJP Plus hanya boleh digunakan untuk buku tulis, buku gambar, buku pelajaran, alat tulis seperti pensil, pulpen, penghapus dan rautan, alat gambar seperti macam-macam penggaris, pensil lwarna, spidol, cat/kertas warna, buku dan atau kertas gambar dan jangka, alat dan atau bahan praktik, seragam sekolah dan kelengkapannya, sepatu dan kaos kaki sekolah, tas sekolah, pakaian olahraga sekolah, buku pelajaran 
penunjang, kudapan bergizi, kacamata sebagai alat bantu penglihatan, alat bantu pendengaran, kalkulator scientific, USB flashdisk sebagai alat simpan data, seragam pramuka dan kelengkapannya, pembayaran kegiatan ekstrakurikuler yang tidak dibiayai oleh Biaya Operasional Pendidikan dan Bantuan Operasional Sekolah, komputer/Laptop.

Berikut merupakan daftar jenis toko dan macam barang yang dapat dibeli dengan menggunakan Kartu Jakarta Pintar Plus (KJP Plus) :

\begin{tabular}{|c|l|l|}
\hline No & Jenis Toko \& Penggunaan & \multicolumn{1}{c|}{ Keterangan } \\
\hline 1 & Alat-alat Kesehatan & $\begin{array}{l}\text { Peralatan penunjang kesehatan (perawatan } \\
\text { kesehatan gigi, alat bantu pendengaran, alat bantu } \\
\text { berjalan, dll). }\end{array}$ \\
\hline 2 & Apotek/Toko Obat & Obat-obatan dan vitamin. \\
\hline 3 & Optik & Alat bantu pengelihatan (kacamata). \\
\hline 4 & Toko Busana/Toko Sepatu & Seragam, sepatu sekolah, dan kelengkapannya. \\
\hline 5 & Departement Store & Seragam, sepatu sekolah, dan kelengkapannya. \\
\hline 6 & Supermarket/Foodstore & $\begin{array}{l}\text { Makanan dan minuman bergizi. Peralatan } \\
\text { kebutuhan sekolah. }\end{array}$ \\
\hline 7 & Toko Buku & $\begin{array}{l}\text { Kebutuhan buku siswa (buku tulis, buku latihan } \\
\text { soal, buku gambar, buku pelajaran). }\end{array}$ \\
\hline 8 & Alat Tulis & $\begin{array}{l}\text { Kebutuhan alat tulis siswa (alat tulis, alat gambar, } \\
\text { alat dan bahan praktik). }\end{array}$ \\
\hline 9 & Kebutuhan Olah Raga & $\begin{array}{l}\text { Seragam dan peralatan olahraga yang menunjang } \\
\text { pelajaran olahraga di sekolah. }\end{array}$ \\
\hline 10 & Kegiatan & $\begin{array}{l}\text { Ekstra Kurikuler yang tidak dibiayai oleh BOP dan } \\
\text { BOS }\end{array}$ \\
\hline 11 & Toko Komputer & Komputer / Laptop \\
\hline
\end{tabular}

Dari pemaparan beberapa jenis kebutuhan yang diperbolehkan untuk belanja dana KJP, artinya hal tersebut telah sesuai dengan Amandemen UUD 1945, bahwa setiap warga negara berhak mendapat pendidikan, dan pemerintah wajib membiayainya. Semoga pemerintah di Provinsi lainnya dapat ikut serta dalam mewujudkan amanat amandemen tersebut.

\section{e. Manfaat KJP}

Manfaat dan dampak positif yang diharapkan dari siswa penerima KJP yaitu: 1). Seluruh warga DKI Jakarta menamatkan pendidikan minimal sampai dengan jenjang SMA/SMK; 2). Mutu Pendidikan di Provinsi DKI Jakarta meningkat secara signifikan; 3). Peningkatan pencapaian target Angka Partisipasi Kasar (APK) pendidikan dasar dan menengah.

KJP Plus diharapkan dapat: 1). Meningkatkan akses bagi anak usia 6 sampai dengan 21 tahun untuk mendapatkan layanan pendidikan sampai tamat satuan pendidikan menengah untuk mendukung pelaksanaan Pendidikan Menengah Universal/Rintisan Wajib Belajar 12 Tahun; 2). Meringankan biaya personal pendidikan; 3). Mencegah peserta didik dari kemungkinan putus sekolah (drop out) atau tidak melanjutkan pendidikan akibat kesulitan ekonomi; 4). Mendorong siswa putus sekolah (drop out) atau anak tidak sekolah agar mendapatkan layanan pendidikan di sekolah/Sanggar 
Kegiatan Belajar (SKB)/Pusat kegiatan Belajar Masyarakat (PKBM)/Lembaga Kursus dan Pelatihan (LKP) atau satuan pendidikan nonformal lainnya; 5). Meningkatkan pencapaian target Angka Partisipasi Kasar Pendidikan Dasar dan Menengah; dan 6). Meningkatkan kesiapan siswa pendidikan menengah maupun peserta pendidikan kesetaraan dan kursus untuk memasuki pasar kerja atau melanjutkan ke jenjang pendidikan tinggi.

\section{f. Dana KJP di APBD 2018 naik}

Dalam anggaran Bantuan Sosial (Bansos), baik dalam dokumen Finalisasi Forum Sinkronisasi hingga Input Hasil Pembahasan Banggar DPRD, bantuan biaya personal pendidikan melalui Kartu Jakarta Pintar (KJP) selalu mendapatkan porsi paling besar. Pada rancangan pertama dan kedua, pos ini mendapatkan alokasi dana sebesar Rp3,42 triliun dan meningkat sebesar Rp560,25 miliar menjadi Rp3,98 triliun pada rancangan ketiga. Bahkan, pos ini menjadi satu-satunya anggaran Bantuan Sosial yang mendapatkan tambahan dana. ${ }^{10}$

\section{Tantangan KJP/KJP Plus}

Keberhasilan pembangunan ekonomi suatu wilayah dapat diukur melalui beberapa indikator, seperti tinggi pertumbuhan ekonomi dan pendapatan perkapita, semakin terbukanya kesempatan kerja sehingga dapat menekan pengangguran, menurunnya jumlah penduduk yang hidup di bawah kemiskinan absolute, pergeseran struktur ekonomi ke arah yang lebih modern, dan semakin besarnya kemampuan keuangan untuk membiayai administrasi pemerintah dan kegiatan pembangunan. ${ }^{11}$

Sejak mulai diluncurkan pada tahun 2012, program KJP menuai pro dan kontra, tanggapan positif dan negatif mulai berdatangan. Dana KJP dinilai sebagai pemborosan dana, karena Badan Pemeriksa Keuangan (BPK) menyebut ada 9.006 penerima ganda, dengan nama anak dan nama ibu kandung yang identik. Kerugiannya senilai Rp. 13, 34 milyar. ${ }^{12}$ Masalah ini dapat terselesaikan manakala pendataan KJP menggunakan aplikasi yang tepat untuk menghindari penerima KJP ganda.

Permasalahan-permasalahan juga turut menegaskan eksistensi KJP. Banyak penyelewengan dan kejanggalan yang ditemukan. Diantaranya, besaran anggaran bantuan berkurang hingga jumlah penerima tidak sesuai dengan fakta di sekolah. Sophia dalam papernya menemukan bahwa Forum Musyawarah Guru Jakarta (FMGJ) menemukan salah satu kasus di SMP di Jakarta Timur, 17 orang dari 27 orang siswa penerima KJP yang seharusnya menerima Rp. 210.000,- berkurang menjadi Rp. 180.000,- setelah dipangkas sekolah dengan alasan dipotong administrasi. ${ }^{13}$

Dinas Pendidikan (Disdik) Pemprov DKI Jakarta menemukan 27 ribu kasus penyimpangan dana program KJP yang jumlahnya mencapai Rp. 2 Triliun. Penyebabnya adalah proses pemberian Surat Keterangan Tidak Mampu (SKTM) sebagai salah satu syarat penerimaan KJP amat dimudahkan dari pihak RT dan kelurahan, dan tidak tepat sasaran. ${ }^{14}$ Hal ini memberikan antisipasi bagi pihak sekolah, untuk memutuskan siapa

\footnotetext{
${ }^{10}$ Kurniawan.

11 Soekarni dan Mahmud, "Studi Kelayakan Ekonomi Pembentukan Provinsi Baru: Kasus Banten." 67.

12 T.t.

${ }^{13}$ Sophia, Paper: Kartu Jakarta Pintar. 6.

14 "lipsus.kompas.com."
} 
yang layak mendapatkan KJP, dan setelah dinyatakan layak baru diminta SKTM dengan rekomendasi dari sekolah.

DPRD DKI Jakarta juga menemukan penyalahgunaan dana KJP, dimana para pemegangnya telah menukar bantuan dana pendidikan dengan uang tunai dan digunakan untuk hal-hal yang tidak berhubungan dengan alokasi dana KJP. Bank DKI turut juga menghimbau toko-toko atau pusat perbelanjaan maupun Stasiun Pengisian Bahan Bakar Umum (SPBU) tidak menerima pembayaran dengan kartu ATM Bank DKI yang bertanda KJP. ${ }^{15}$

Mantan Gubernur DKI Jakarta sebelumnya, Basuki Tjahaya Purnama atau Ahok, menilai program KJP Plus sebagai suatu pemborosan, karena ada pembiayaan untuk anak usia sekolah yang putus/tidak sekolah.

\section{KESIMPULAN}

Manusia merupakan produk pendidikan. Siapapun yang kita temui dalam keseharian kita merupakan output dari proses pendidikan. Kompetensi manusia amat beragam, dikarenakan perbedaan yang tak terhingga, baik dari sisi minat dan bakat, diantaranya perbedaan Namun tidak semua manusia terproses dari memiliki kesempatan mendapatkan pendidikan karena terdapat perbedaan-perbedaan dari manusia.

Tak dapat dipungkiri bahwa pendidikan cenderung menjadi salah satu sarana stratafikasi sosial selain kekayaan, kekuasaan dan keturunan. Tingkat pendidikan dapat menentukan status sosial seseorang di masyarakat. Dalam masyarakat yang menghargai ilmu pengetahuan/pendidikan, orang yang berpendidikan akan mendapat penghargaan lebih besar dibanding mereka yang tidak berpendidikan. Orang yang tingkat pendidikannya tinggi akan lebih dihargai dan dihormati dalam masyarakat. Sebaliknya, orang yang tingkat pendidikannya rendah kurang dihargai dalam masyarakat.

Penduduk miskin/kurang mampu yang menjadi warga DKI Jakarta layak mengapresiasi kepedulian Pemerintah Provinsinya, dimana lewat tangan Gubernur dan Wakil Gubernur yang terpilih sejak tahun 2012 hingga sekarang dalam meningkatkan kualitas Sumber Daya Manusia yang akan memajukan DKI Jakarta sebagai miniatur Negara Kesatuan Republik Indonesia.

Berbagai manfa'at telah dirasakan oleh penerima dana bantuan KJP, baik siswa maupun orang tua. Hal inipun ternyata berdampak positif terhadap peningkatan nilai ekonomi khususnya pedagang. Sehingga program KJP ini dapat dikatakan sebagai bentuk nyata dari simbiosis mutualisme yang tercipta di Provinsi DKI Jakarta dari sisi pendidikan.

\section{DAFTAR PUSTAKA}

"Badan Pusat Statistik Provinsi DKI Jakarta, Statistik Kesejahteraan Rakyat Provinsi DKI Jakarta 2017," t.t.

Daroesman, Ruth. Pembiayaan Pendidikan di Indonesia: Sebuah Studi tentang Sumber dan Penggunaan Pembiayaan Pendidikan. Jakarta: PT. Badan Penerbit Indonesia Raya, 1974.

"https://id.wikipedia.org," t.t.

“Instruksi KADISDIK Nomor 1 Tahun 2017," t.t.

Kurniawan, Frendy. https://tirto.id/melihat-porsi-anggaran-terbesar-dalam-rancanganapbd-dki-jakarta, t.t. https://tirto.id.

$$
{ }^{15} \text { T.t. }
$$


"lipsus.kompas.com," 14 Oktober 2016. http://lipsus.kompas.com.

Mulyono. Konsep Pembiayaan Pendidikan. Jogjakarta: Ar-Ruzz Media, 2016.

Soekarni, dan Mahmud. "Studi Kelayakan Ekonomi Pembentukan Provinsi Baru: Kasus Banten." Jurnal Ekonomi dan Pembangunan (JEP) I (2000).

Sophia, Handynieta. Paper: Kartu Jakarta Pintar. Yogyakarta: FKIP Universitas Sanata Dharma, 2014.

"Surat Edaran Nomor SE/3/2017," t.t. http://jakartamajubersama.com-Tim

Anies-Sandi, $\quad$ Peb 2017. http://jakartamajubersama.com.

kjp.jakarta.go.id, t.t.

http://news.okezone.com, t.t.

megapolitan.kompas.com, t.t. 
IMPLEMENTASI DANA KARTU JAKARTA PINTAR (KJP)

(Sebuah Analisis Kebijakan Pendidikan)

58 Al Amin: Jurnal Kajian Ilmu dan Budaya Islam, Volume 2, No 1, 2019 